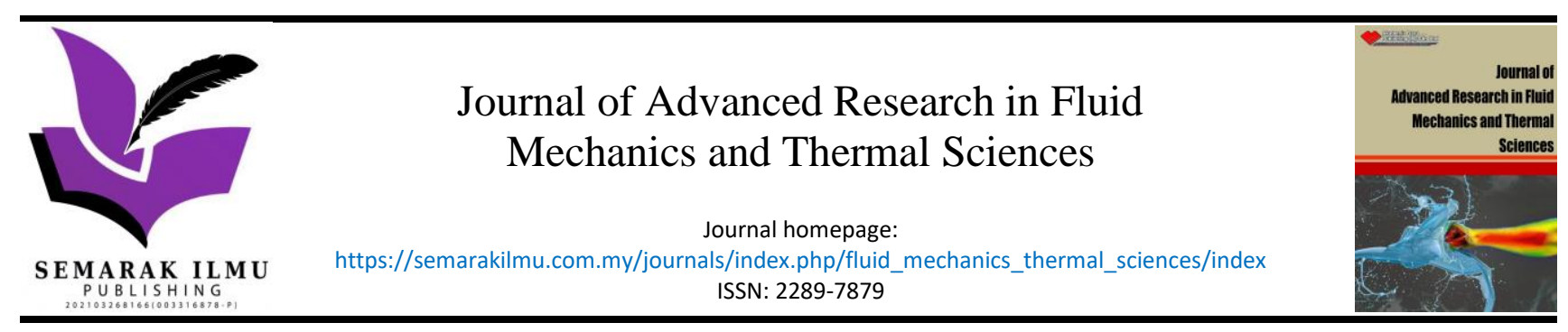

\title{
Evaluation of Pressure Drop of Two-Phase Flow Boiling with R290 in Horizontal Mini Channel
}

\author{
Fajriocta Umar ${ }^{1}$, Jong Taek Oh², Agus Sunjarianto Pamitran ${ }^{1, *}$ \\ Department of Mechanical Engineering, Universitas Indonesia Indonesia, Kampus UI Depok 16424, Indonesia \\ 2 Department of Refrigeration and Air Conditioning Engineering, Chonnam National University, San 96-1, Dunduk-Dong, Yeosu, Chonnam 550-749, \\ South Korea
}

\section{\begin{tabular}{l} 
ARTICLE INFO $\quad$ ABSTRACT \\
\hline
\end{tabular}}

\section{Article history:}

Received 30 April 2021

Received in revised form 27 October 2021

Accepted 4 November 2021

Available online 4 December 2021

\section{Keywords:}

Pressure drop; R290; Two-phase flow boiling; Mini channel; Correlation

\begin{abstract}
Various experiments on the pressure drop of a two-phase flow boiling in a mini channel tube have been carried out. This study is aimed at characteristics of the pressure drop of a two-phase flow boiling using a refrigerant R290. The experiment uses a horizontal, stainless steel, 2-m-long mini-channel tube with a 3-mm inner diameter. The experiment has been carried out using various data with the vapor qualities ranging from 0.1 to 0.9 , the mass fluxes ranging $50 \mathrm{~kg} / \mathrm{m}^{2} \mathrm{~s}$ to $180 \mathrm{~kg} / \mathrm{m}^{2} \mathrm{~s}$, and the heat fluxes ranging from 5 $\mathrm{kW} / \mathrm{m}^{2}$ to $20 \mathrm{~kW} / \mathrm{m}^{2}$. Furthermore, several homogeneous and separated methods were used to predict the experimental data. Li and Hibiki's correlation give the best overall deviation pressure drop value is the most accurate with its deviation amounting $19.47 \%$.
\end{abstract}

\section{Introduction}

Flow tube-related discussions do not preclude the study of a pressure drop since the pressure drop will affect the increased energy required by the circulating fluid. The pressure drop can occur in the flowing of a two-phase flow in a horizontal tube. Ghiaasiaan et al., [1] concluded that it was difficult to measure and correlate the frictional pressure drop in a small channel due to several reasons, namely there was an uncertainty in the wall roughness, in the inlet and outlet pressure, and in the acceleration pressure, and the occuring of laminar flow in a mini channel and a microchannel.

Many studies on the pressure drop [2-10] have been published. Lee et al., [11] and Bashar et al., [12] pointed out that, since a friction occurred at a certain mass flux, the pressure drop characteristics had been better enhanced in a small diameter tube. An increased saturation temperature would reduce the pressure drop [13]. Moreover, Padilla et al., [14] and Qu et al., [15] also observed that, in the low vapor quality region, the pressure drop increased slightly, and, in various mass fluxes, the pressure drop linearly increased.

Natural refrigerants play an important role in the cooling system technology. This study used R290 or propane as the working fluid; as a matter of a fact, very few researchers have used a mini

\footnotetext{
* Corresponding author.

E-mail address: pamitran@eng.ui.ac.id

https://doi.org/10.37934/arfmts.89.2.160166
} 
channel tube and R290 as their working fluid in their studies. The ozone depletion potential (ODP) of R290 was zero, and the global warming potential (GWP) was low, too. Therefore, it would not damage the atmosphere. In fact, it played an important role in the compressor and refrigerant mass flow rate by $50 \%$. Moreover, it had a higher cooling capacity than that of R22 [16-17].

This study was aimed at obtaining the characteristics of the pressure drop of a two-phase flow boiling using an R290 refrigerant. The pressure drop correlations of the homogeneous and separated methods were used to predict the experimental data, so it was possible to identify which of the correlations had the best prediction.

\section{Methodology}

\subsection{Experimental Set Up}

In this study, the data obtained from Pamitran et al., [18] in the form of pressure and temperature distribution so that the data can be calculated using existing correlations. Figure 1 showed the experimental setup used in this study. The experimental components included a condenser, a subcooler, a refrigerant pump, a receiver, a mass flow meter, a heater, and a test section where the mass flow of the refrigerant was controlled by a needle valve. Moreover, a coriolis mass flow meter was installed to measure the mass flow of the refrigerant. A preheater was installed to control the mass vapor quality of the refrigerant by heating the refrigerant before it entered the test section. The test section is a stainless steel, 2-m-long tube having a smooth surface, with a 3-mm inner diameter. The experiment was carried out using various data with the vapor qualities ranging from 0.1 to 0.9 , the mass flux ranging from $50 \mathrm{~kg} / \mathrm{m}^{2} \mathrm{~s}$ to $180 \mathrm{~kg} / \mathrm{m}^{2} \mathrm{~s}$, and the heat flux from $5 \mathrm{~kW} / \mathrm{m}^{2}$ to $20 \mathrm{~kW} / \mathrm{m}^{2}$. The sight glass with the same inner diameter as that of the test section was connected to the inlet and outlet to display the flow.

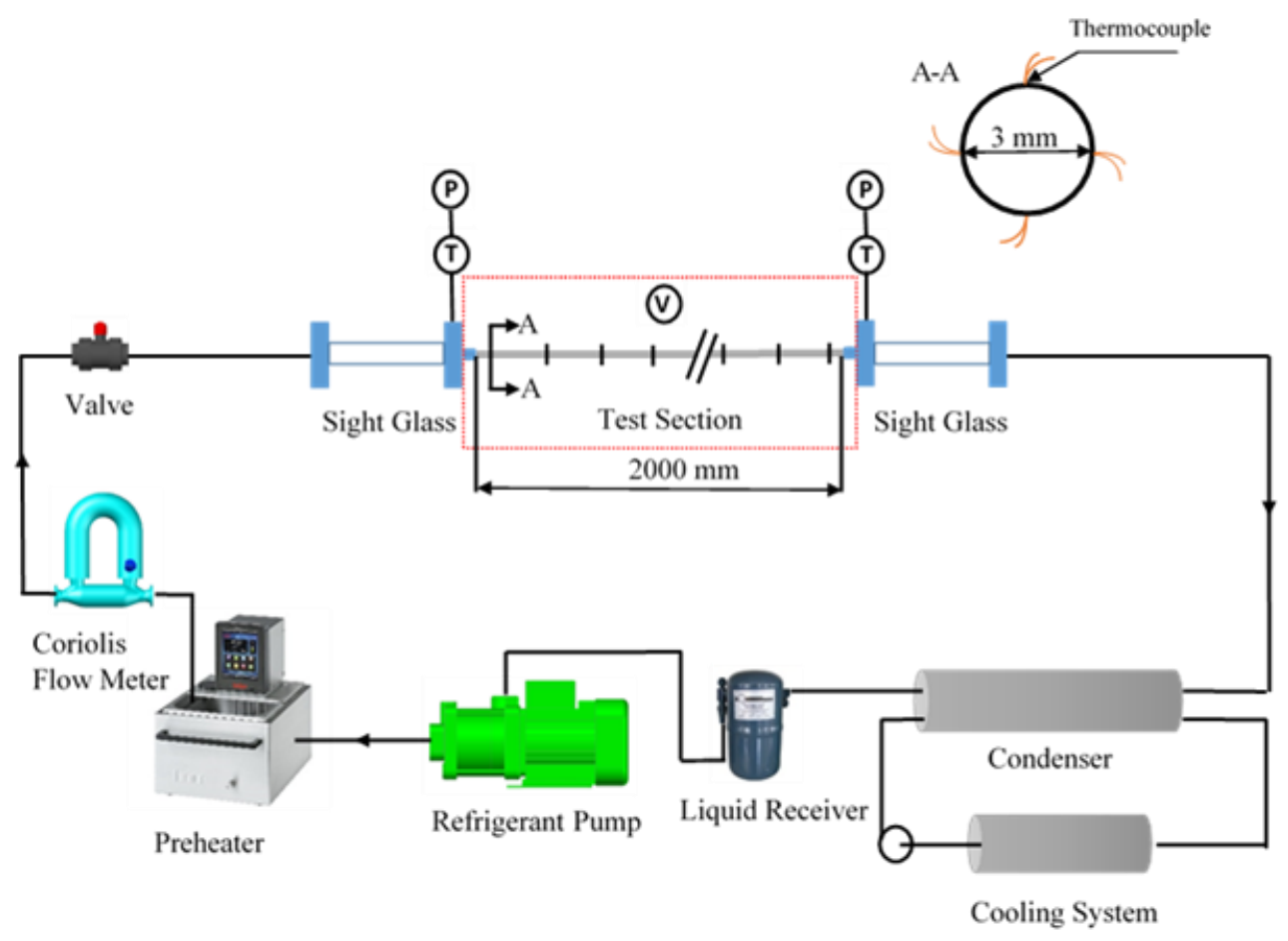

Fig. 1. Experimental setup 


\subsection{Two-Phase Frictional Pressure Gradient Correlations}

Several homogeneous and separated methods of a pressure drop correlation could be used to predict the experimental data. All of the employed correlations were modified based on the pressure drop correlations, and the pressure drop correlations were adjusted in accordance with each author's conditions in their study due to various working fluids and diameters that they used. Park and Hrnjak [19] used a 6.1-mm diameter, while Kim and Mudawar [21] used diameters ranging from $0.3 \mathrm{~mm}$ to $5.35 \mathrm{~mm}$. Moreover, Li and Hibiki [20], Hwang and Kim [22], and Bashar et al., [12] used a smallerthan-3-mm diameter. All of the diameters that they used were still within the range of a mini channel tube. Furthermore, they used mass fluxes ranging from $33 \mathrm{~kg} / \mathrm{m}^{2} \mathrm{~s}$ to $2738 \mathrm{~kg} / \mathrm{m}^{2} \mathrm{~s}$ and heat fluxes ranging from $5 \mathrm{~kW} / \mathrm{m}^{2}$ to $500 \mathrm{~kW} / \mathrm{m}^{2}$. Table 1 showed the correlations between the two-phase friction pressure gradient of the homogeneous method and the separation method.

\section{Table 1}

The Pressure Drop Correlation

\begin{tabular}{ll}
\hline Auhor(s) & Equation \\
\hline Bashar et al., [12] & $\left(\frac{d p}{d z}\right) F=\emptyset_{v}^{2}\left(\frac{d p}{d z}\right) v$ and $\emptyset_{v}^{2}=1+C X_{t t}^{n}+X_{t t}^{2}$ \\
& $C=21\left\{\left(1-\exp \left(-0,28 B o^{0,5}\right)\right\}\left\{\left(1-0,45 \exp \left(-0,02 F r^{1,2}\right)\right)\right\}\right.$ \\
& $n=\{1-0,87 \exp (-0,001 F r)\} B o$ \\
Park and Hrnjak [19] & $\left(\frac{d P}{d z}\right) F=\left(\frac{d P}{d z}\right)_{l o}(1-2 x)(1-x)^{\frac{1}{3}}+\left(\frac{d P}{d z}\right)_{v o}\left[2 x(1-x)^{\frac{1}{3}}+x^{3}\right]$ \\
& $\left(\frac{d P}{d z}\right)_{l o}=0,079\left(\frac{\mu_{f}}{G D}\right)^{0,25}\left(\frac{2 G^{2}}{D \rho_{f}}\right)$ \\
& $\left(\frac{d P}{d z}\right)_{v o}=0,079\left(\frac{\mu_{g}}{G D}\right)^{0,25}\left(\frac{2 G^{2}}{D \rho_{g}}\right)$
\end{tabular}

Condition
R134a and R1234yf
$D_{i}: 2,14 \mathrm{~mm}$
$G: 50-200 \mathrm{~kg} / \mathrm{m}^{2} \mathrm{~s}$
$q: 5-15 \mathrm{~kW} / \mathrm{m}^{2}$

Li and Hibiki [20]

$$
\begin{aligned}
& \left(\frac{\mathrm{dp}}{\mathrm{dz}}\right) \mathrm{tp}=\emptyset_{\mathrm{l}}^{2}\left(\frac{\mathrm{dp}}{\mathrm{dz}}\right) f \text { and } \emptyset_{\mathrm{l}}^{2}=1+\frac{\mathrm{c}}{\mathrm{x}}+\frac{1}{\mathrm{x}^{2}} \\
& \left(\frac{\mathrm{dp}}{\mathrm{dz}}\right) \mathrm{l}=\mathrm{f}_{f} \frac{2 \mathrm{G}^{2}(1-\mathrm{x})^{2}}{\mathrm{D} \rho_{f}} \text { and }\left(\frac{\mathrm{dp}}{\mathrm{dz}}\right) g=\mathrm{f}_{g} \frac{2 \mathrm{G}^{2} \mathrm{x}^{2}}{\mathrm{D} \rho_{g}} \\
& C_{\mathrm{tt}}=6,28 \mathrm{~N} \mu_{\mathrm{tp}}^{0,14} \mathrm{Re}_{\mathrm{tp}}^{0,67} \mathrm{x}^{0,42} C_{\mathrm{tv}}=1,54 \mathrm{~N} \mu_{\mathrm{tp}}^{0,14} \operatorname{Re}_{\mathrm{tp}}^{0,52} \mathrm{x}^{0,32} \\
& C_{\mathrm{vt}}=245,5 \mathrm{~N} \mu_{\mathrm{tp}}^{0,75} \mathrm{Re}_{\mathrm{tp}}^{0,35} \mathrm{x}^{0,54} C_{v v}=41,7 \mathrm{~N} \mu_{\mathrm{tp}}^{0,66} \mathrm{Re}_{\mathrm{tp}}^{0,42} \mathrm{x}^{0,21}
\end{aligned}
$$

R410a, R22, and Co2

$D_{i}: 6.1 \mathrm{~mm}$

$\mathrm{G}: 100-400 \mathrm{~kg} / \mathrm{m}^{2} \mathrm{~s}$

$\mathrm{q}: 5-15 \mathrm{~kW} / \mathrm{m}^{2}$

Kim and Mudawar

[21]

$$
\begin{aligned}
& \left(\frac{d P}{d z}\right) F=\left(\frac{d P}{d z}\right) f \emptyset_{f}^{2} \text { and } \emptyset_{\mathrm{f}}^{2}=1+\frac{\mathrm{c}}{\mathrm{x}}+\frac{1}{\mathrm{x}^{2}} \\
& \left.X^{2}=\frac{(d P / d z) f}{(d P / d z}\right),-\left(\frac{d P}{d z}\right) f=\frac{2 f_{f} v_{f} G^{2}(1-x)^{2}}{D_{h}} \\
& -\left(\frac{d P}{d z}\right) g=\frac{2 f_{g} v_{g} G^{2} x^{2}}{D_{h}} \\
& \mathrm{C}=\mathrm{C}_{\text {non-boiling }}\left[1+60 W e_{f o}^{0,32}\left(B o \frac{P_{H}}{P_{F}}\right)^{0,78}\right]_{\text {for }}, R e_{f} \geq 2000 \\
& \mathrm{C}=\mathrm{C}_{\text {non-boiling }}\left[1+530 W e_{f o}^{0,52}\left(B o \frac{P_{H}}{P_{F}}\right)^{1,09}\right]_{\text {for },} R e_{f}<2000
\end{aligned}
$$

$R 22, R 134 a, R 410 A$, R290, R744, R245fa, ammonia, nitrogen, and water

$D_{h}: 0.1-2.98 \mathrm{~mm}$

$\mathrm{G}: 50-950 \mathrm{~kg} / \mathrm{m}^{2} \mathrm{~s}$ $\mathrm{q}: 5-500 \mathrm{~kW} / \mathrm{m}^{2}$

R12, R134a R22, R245fa, R410A, FC-72, ammonia, $\mathrm{CO}_{2}$, and water $D_{h}: 0.349-5.35 \mathrm{~mm}$ $\mathrm{G}: 33-2738 \mathrm{~kg} / \mathrm{m}^{2} \mathrm{~s}$

Hwang and $\operatorname{kim}[22] \quad\left(\frac{d P}{d z}\right) F=\left(\frac{d P}{d z}\right) f \emptyset_{f}^{2}$ and $\emptyset_{\mathrm{f}}^{2}=1+\frac{\mathrm{c}}{\mathrm{x}}+\frac{1}{\mathrm{x}^{2}}$

$$
C=0,227 R e_{l}^{0,452} X^{-0,32} N_{\text {conf }}^{-0.82} N_{\text {conf }}=\sqrt{\frac{\sigma}{\mathbb{g}\left(\rho_{f}-\rho_{g}\right)}} / D_{i}
$$

R134a

$\mathrm{D}_{\mathrm{i}}=0.244 \mathrm{~mm}, 0.430$ $\mathrm{mm}, 0.792 \mathrm{~mm}$ $\mathrm{G}: 140-950 \mathrm{~kg} / \mathrm{m}^{2} \mathrm{~s}$ 


\section{Results and Discussion}

This experiment used a homogeneous method and a separated method to obtain the relevant comparative data by employing various heat fluxes ranging from $5 \mathrm{~kW} / \mathrm{m}^{2}$ to $20 \mathrm{~kW} / \mathrm{m}^{2}$ and various mass fluxes ranging from $50 \mathrm{~kg} / \mathrm{m}^{2} \mathrm{~s}$ to $180 \mathrm{~kg} / \mathrm{m}^{2} \mathrm{~s}$, and various vapor qualities ranging from 0.1 to 0.9. Due to the researchers' different conditions, all of the existing correlations would result in different correlations.

The experimental pressure drop of the characteristics was compared to one another with the heat flux of $10.28 \mathrm{~kW} / \mathrm{m}^{2}$ and the mass fluxes ranging from $60 \mathrm{~kg} / \mathrm{m}^{2} \mathrm{~s}$ to $100 \mathrm{~kg} / \mathrm{m}^{2} \mathrm{~s}$ as shown by Figure 2. Moreover, the figure showed that the higher the mass flux was, the higher the value of the pressure gradient would be.

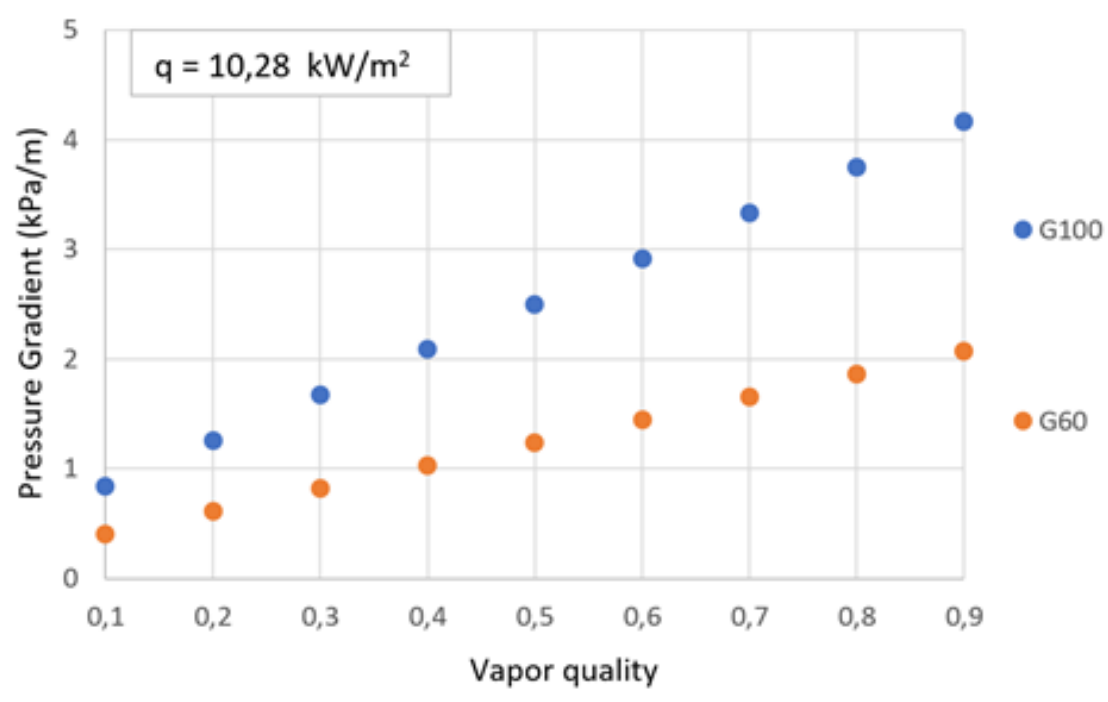

Fig. 2. Characteristic of the R290 pressure drop at different mass fluxes with the saturation temperatures ranging from $8.7^{\circ} \mathrm{C}$ to $10.8^{\circ} \mathrm{C}$ and the heat flux of $10.28 \mathrm{~kW} / \mathrm{m}^{2}$

Figure 3 showed a comparison between the prediction with existing correlations of the pressure gradients and that of the experiment using R290 as the working fluid at several saturation temperatures and a constant heat flux. Moreover, the constant mass flux was $169.85 \mathrm{~kg} / \mathrm{m}^{2} \mathrm{~s}$, and the saturation temperatures ranged from $9.5^{\circ} \mathrm{C}$ to 8.7. The figure showed that the higher the vapor quality was, the higher the pressure gradient would be.

Kim and Mudawar [21]'s correlation provided a significantly-increased pressure gradient when the vapor quality was 0.3 and the deviation was $37.32 \%$. The prediction pressure gradient with Hwang and Kim [22]'s correlation decreased when the vapor quality was 0.55 and the deviation was 41.98\%. The prediction pressure gradient with Bashar et al., [12]' correlation and Park and Hrnjak [18]'s correlation increased when the vapor quality increased. the deviation Bashar et al., and Park and Hrnjak value amounting to $42.5 \%$ and $39.98 \%$, respectively. Li and Hibiki [20]'s correlation had the same trend as that of Bashar et al., and Park and Hrnjak, but these values were related to the experimental data. Moreover, the pressure gradient continued to increase when the vapor quality increased with the deviation of $13.53 \%$. 


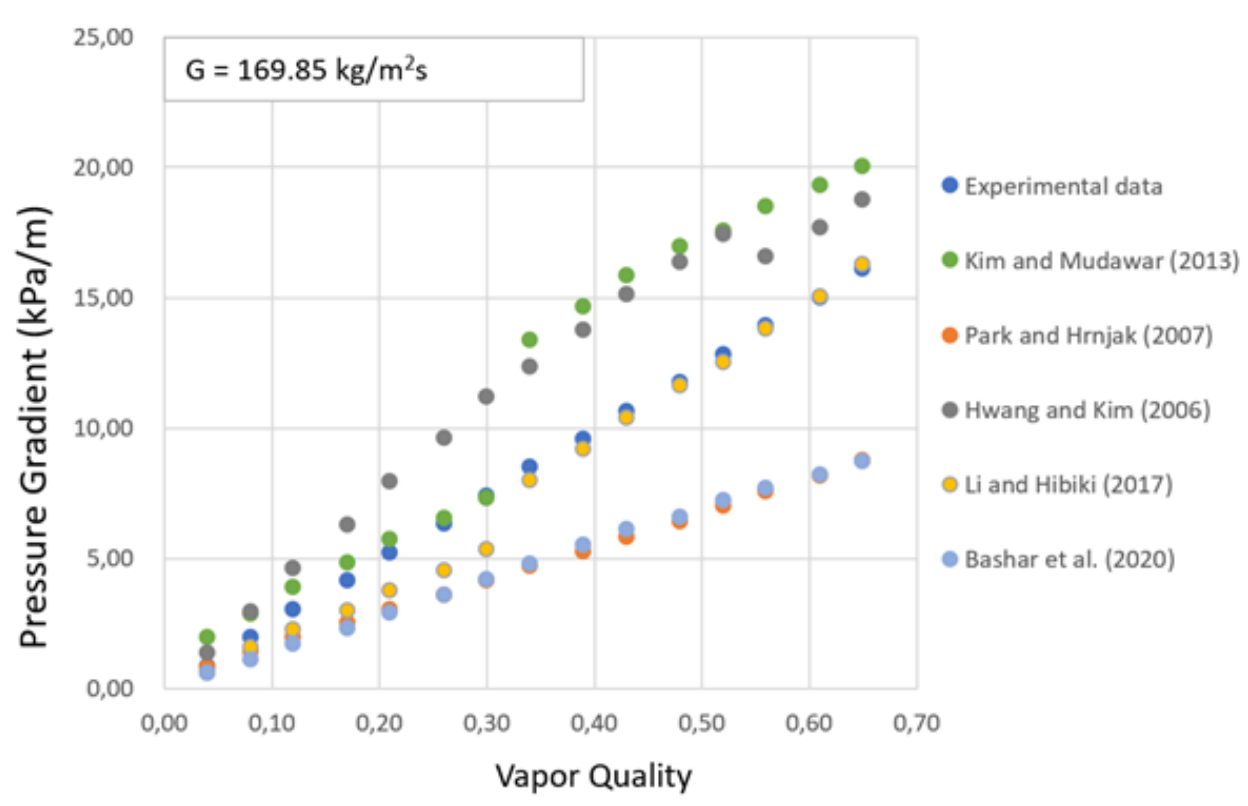

Fig 3. Comparison between the existing correlations of R290 pressure gradient and that of the experiment with the constant mass flux of $169.85 \mathrm{~kg} / \mathrm{m}^{2} \mathrm{~s}$ and the saturation temperatures ranging from $8.7{ }^{\circ} \mathrm{C}$ to $9.5^{\circ} \mathrm{C}$

Figure 4 showed the comparison between the existing correlations of the pressure gradient and that of the experiment using R290 as their working fluid at several saturation temperatures and a constant heat flux when the constant mass flux was $113.23 \mathrm{~kg} / \mathrm{m}^{2} \mathrm{~s}$ and the saturation temperatures ranged from $9.97{ }^{\circ} \mathrm{C}$ to $9.58{ }^{\circ} \mathrm{C}$. Moreover, the figure showed that the higher the vapor quality was, the higher the pressure gradient would be.

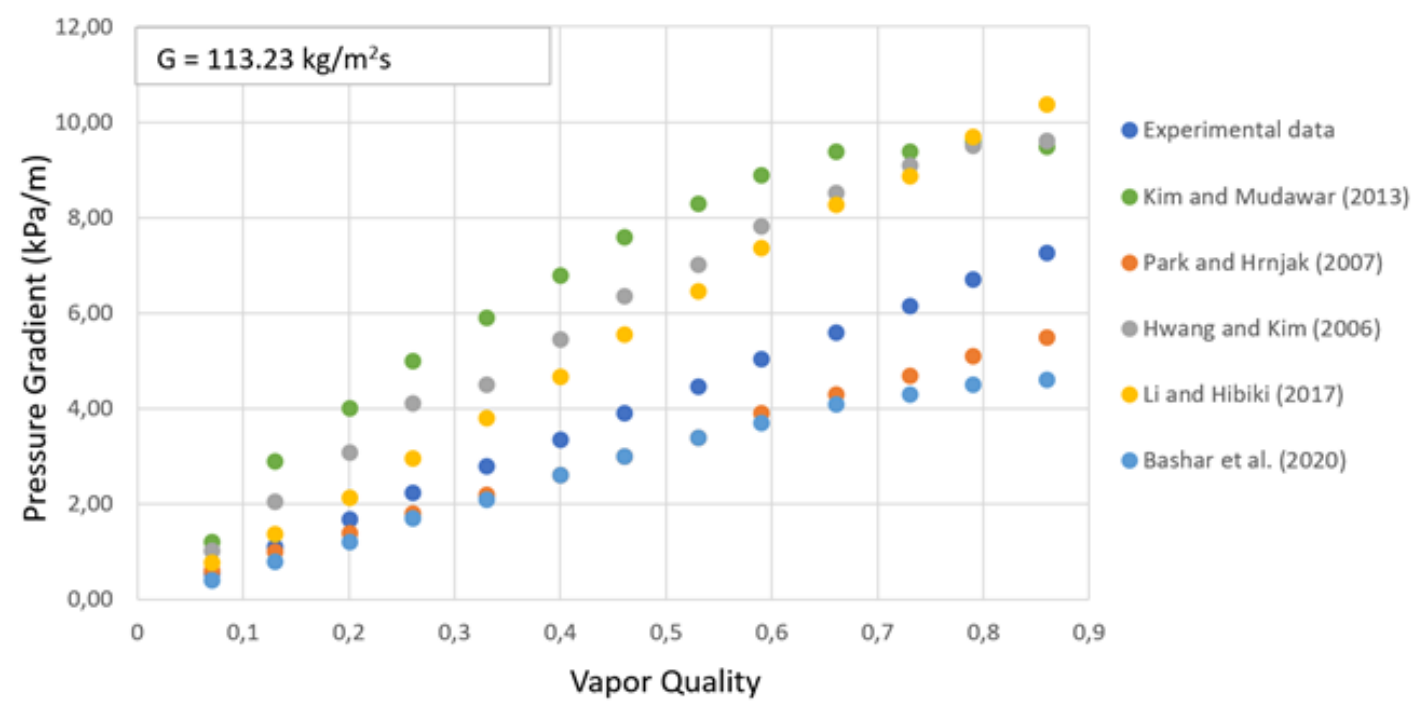

Fig 4. Comparison between the prediction with existing correlations of R290 pressure gradient and that of the experiment with the constant mass flux amounting to 113.23 $\mathrm{kg} / \mathrm{m}^{2} \mathrm{~s}$ and the saturation temperatures ranging from $9.97{ }^{\circ} \mathrm{C}$ to $9.58{ }^{\circ} \mathrm{C}$ 
The correlation of Li and Hibiki [20] provides an increased pressure gradient with the deviation is $11.48 \%$, followed by the correlation of Kim and Mudawar [21] and Hwang and Kim [22], which have the same trend, and the deviation is $19.11 \%$ and $22.83 \%$ respectively. The correlation of Bashar et al., [12] has the same trend as Park and Hrnjak [19], and the pressure gradient continues to increase with the increase of vapor quality, with the deviations is $42.8 \%$ and $35.84 \%$, respectively.

Table 2 showed the deviation between the existing correlations of the pressure gradient and that of the experiment using R290 as their working fluid. it can be seen that the results of Li and Hibiki give the best prediction where the correlation used separated method and as shown in table 1 that $\mathrm{Li}$ and Hibiki use the diameters ranging from $0.1 \mathrm{~mm}$ to $2.98 \mathrm{~mm}$ while the value of mass flux 50 to $950 \mathrm{~kg} / \mathrm{m}^{2} \mathrm{~s}$.

\section{Table 2}

The Deviation of Pressure Drop

\begin{tabular}{llllll}
\hline Author (s) & Bashar et al., & Park and Hrnjak & Li and Hibiki [19] & Kim and & Hwang and kim \\
& {$[12]$} & {$[18]$} & & Mudawar [20] & {$[21]$} \\
Deviation (\%) & 31.82 & 43.94 & 19.47 & 24.46 & 50.37 \\
\hline
\end{tabular}

\section{Conclusions}

This study was aimed at obtaining the characteristics of the pressure drop of a two-phase flow boiling using an R290 refrigerant. Accordingly, the pressure drop correlations of a homogeneous method and a separated method were used to predict the experimental data. Li and Hibiki's correlation was the most accurate since, with overall deviation of $19.47 \%$ with R290 used as the working fluid and the diameters ranging from $0.1 \mathrm{~mm}$ to $2.98 \mathrm{~mm}$. As a matter of a fact, they were confirmed to be in the range of a mini channel tube. Under a constant heat flux and several saturation temperatures, the pressure gradients of R290 were compared to one another, and the result showed that the higher the vapor quality was, the higher the value would be.

\section{Acknowledgement}

This research is funded by International Research Collaboration Grant of Universitas Indonesia based on a letter agreement number NKB-1951/UN2.R3.1/HKP.05.00/2019.

\section{References}

[1] Ghiaasiaan, S. Mostafa. Two-phase flow, boiling, and condensation: in conventional and miniature systems. Cambridge University Press, 2007. https://doi.org/10.1017/9781316597392

[2] Yu, W., D. M. France, M. W. Wambsganss, and J. R. Hull. "Two-phase pressure drop, boiling heat transfer, and critical heat flux to water in a small-diameter horizontal tube." International Journal of Multiphase Flow 28, no. 6 (2002): 927-941. https://doi.org/10.1016/S0301-9322(02)00019-8

[3] Li, Wei, and Zan Wu. "Generalized adiabatic pressure drop correlations in evaporative micro/minichannels." Experimental Thermal and Fluid Science 35, no. 6 (2011): $866-872$. https://doi.org/10.1016/j.expthermflusci.2010.07.005

[4] Pfund, David, David Rector, Alireza Shekarriz, Aristotel Popescu, and James Welty. "Pressure drop measurements in a microchannel." AIChE Journal 46, no. 8 (2000): 1496-1507. https://doi.org/10.1002/aic.690460803

[5] Tsotsas, E., and Holger Martin. "Thermal conductivity of packed beds: a review." Chemical Engineering and Processing: Process Intensification 22, no. 1 (1987): 19-37. https://doi.org/10.1016/0255-2701(86)80008-3

[6] Sun, Licheng, and Kaichiro Mishima. "Evaluation analysis of prediction methods for two-phase flow pressure drop in mini-channels." In International Conference on Nuclear Engineering, vol. 48159, pp. 649-658. 2008. https://doi.org/10.1115/ICONE16-48210

[7] Bowers, M. B., and Issam Mudawar. "High flux boiling in low flow rate, low pressure drop mini-channel and microchannel heat sinks." International Journal of Heat and Mass Transfer 37, no. 2 (1994): $321-332$. https://doi.org/10.1016/0017-9310(94)90103-1 
[8] Xie, X. L., W. Q. Tao, and Y. L. He. "Numerical study of turbulent heat transfer and pressure drop characteristics in a water-cooled minichannel heat sink." (2007): 247-255. https://doi.org/10.1016/j.applthermaleng.2008.02.002

[9] Yu, W., D. M. France, M. W. Wambsganss, and J. R. Hull. "Two-phase pressure drop, boiling heat transfer, and critical heat flux to water in a small-diameter horizontal tube." International Journal of Multiphase Flow 28, no. 6 (2002): 927-941. https://doi.org/10.1016/S0301-9322(02)00019-8

[10] Zhang, W., T. Hibiki, and K. Mishima. "Correlations of two-phase frictional pressure drop and void fraction in minichannel." International Journal of Heat and Mass Transfer 53, no. 1-3 (2010): $453-465$. https://doi.org/10.1016/i.ijheatmasstransfer.2009.09.011

[11] Lee, Han Ju, and Sang Yong Lee. "Pressure drop correlations for two-phase flow within horizontal rectangular channels with small heights." International journal of multiphase flow 27, no. 5 (2001): $783-796$. https://doi.org/10.1016/S0301-9322(00)00050-1

[12] Bashar, M. Khairul, Keisuke Nakamura, Keishi Kariya, and Akio Miyara. "Development of a correlation for pressure drop of two-phase flow inside horizontal small diameter smooth and microfin tubes." International Journal of Refrigeration 119 (2020): 80-91. https://doi.org/10.1016/j.ijrefrig.2020.08.013

[13] Rahman, M. Mostaqur, Keishi Kariya, and Akio Miyara. "Comparison and development of new correlation for adiabatic two-phase pressure drop of refrigerant flowing inside a multiport minichannel with and without fins." international journal of refrigeration 82 (2017): 119-129. https://doi.org/10.1016/j.ijrefrig.2017.06.001

[14] Padilla, Miguel, Rémi Revellin, Philippe Haberschill, Ahmed Bensafi, and Jocelyn Bonjour. "Flow regimes and twophase pressure gradient in horizontal straight tubes: Experimental results for HFO-1234yf, R-134a and R410A." Experimental Thermal and Fluid Science 35, no. 6 (2011): 1113-1126. https://doi.org/10.1016/i.expthermflusci.2011.03.006

[15] Qu, Weilin, and Issam Mudawar. "Measurement and prediction of pressure drop in two-phase micro-channel heat sinks." International Journal of Heat and Mass Transfer 46, no. 15 (2003): 2737-2753. https://doi.org/10.1016/S0017-9310(03)00044-9

[16] Choudhari, C. S., and S. N. Sapali. "Performance investigation of natural refrigerant R290 as a substitute to R22 in refrigeration systems." Energy Procedia 109 (2017): 346-352. https://doi.org/10.1016/i.egypro.2017.03.084

[17] Aizuddin, Nik, Normah Mohd Ghazali, and Yushazaziah Mohd Yunos. "Analysis of Convective Boiling Heat Transfer Coefficient Correlation of R290." Jurnal Mekanikal (2018).

[18] Pamitran, Agus Sunjarianto, Kwang-Il Choi, Jong-Taek Oh, and Pega Hrnjak. "Characteristics of two-phase flow pattern transitions and pressure drop of five refrigerants in horizontal circular small tubes." International Journal of Refrigeration 33, no. 3 (2010): 578-588. https://doi.org/10.1016/j.ijrefrig.2009.12.009

[19] Park, C. Y., and P. S. Hrnjak. "CO2 and R410A flow boiling heat transfer, pressure drop, and flow pattern at low temperatures in a horizontal smooth tube." International Journal of Refrigeration 30, no. 1 (2007): 166-178. https://doi.org/10.1016/j.ijrefrig.2006.08.007

[20] Li, Xuejiao, and Takashi Hibiki. "Frictional pressure drop correlation for two-phase flows in mini and micro singlechannels." International Journal of Multiphase Flow $90 \quad$ (2017): https://doi.org/10.1016/j.ijmultiphaseflow.2016.12.003

[21] Kim, Sung-Min, and Issam Mudawar. "Universal approach to predicting two-phase frictional pressure drop for mini/micro-channel saturated flow boiling." International Journal of Heat and Mass Transfer 58, no. 1-2 (2013): 718-734. https://doi.org/10.1016/j.ijheatmasstransfer.2012.11.045

[22] Hwang, Yun Wook, and Min Soo Kim. "The pressure drop in microtubes and the correlation development." International journal of heat and mass transfer 49, no. 11-12 (2006): 1804-1812. https://doi.org/10.1016/i.ijheatmasstransfer.2005.10.040 